\title{
The Correlation Between Pegringsingan Weavers Physical Activity with Body Mass Index, Triglycerides, and Cholesterol Levels in Tenganan Village Karangasem Regency
}

\author{
I Gusti Ayu Sri Dhyanaputri ${ }^{1, *}$, Cok Dewi Widhya Hana Sundari ${ }^{1}$, Ida Ayu Made Sri \\ Arjani $^{1}$, Nur Habibah ${ }^{1}$ \\ ${ }^{1}$ Polytechnic of Health Denpasar Bali, Indonesia \\ *Corresponding Author. Email: dhyanap2@gmail.com
}

\begin{abstract}
The Pegringsingan weaving work position is by sitting on the floor with a simple mat and legs straight to the front and done for 6 to 8 hours per day. Low physical activity or sedentary lifestyle can increase the prevalence of obesity which is a risk factor for non-communicable diseases. Body Mass Index is one of the makers of nutritional status related to obesity that can lead to an increase of triglyceride and cholesterol levels that can cause cardiovascular disease. The Objective of this study to determine the correlation between physical activity with Body Mass Index, Triglycerides levels and Cholesterol Levels of Pegringsingan Weavers in Tenganan Village Karangasem Regency. Method of this is a correlation study with cross-sectional design. The study was done to 26 respondents that were chosen by the saturated sampling method. Physical activity is categorized according to the IPAQ category, BMI is measured by anthropometry and triglyceride and cholesterol levels are measured by dialysis autolyzes. The correlation between physical activity with BMI, Triglycerides dan cholesterol levels are analyzed with Spearman Rho. The Results are there is a significant correlation between physical activity with BMI $(\mathrm{p}=0,021 ; \mathrm{r}=-0,451)$, there is a significant correlation between physical activity with triglyceride levels $(p=0,002 ; r=-0,578)$, there is a significant correlation between physical activity with cholesterol levels $(p=0,034 ; r=-0,417)$. The conclusion there is a negative correlation between physical activity with BMI, triglyceride levels and cholesterol levels.
\end{abstract}

Keywords: physical activity, body mass index, Triglycerides levels, cholesterol levels

\section{INTRODUCTION}

Pegringsingan weavings is a heritage home industry that combines art and simple technology fully produced by hand. This Pegringsingan woven fabric is a characteristic of Tenganan village which is not owned by other regions. To make Pegeringsingan weavings is the job of some of the women in Tenganan village, in Manggis sub-district, Karangasem regency [1]. Based on a preliminary survey, the weaving process is done by women workers by themselves, starting from making the threads, coloring, and weaving [2]. Weaving is a manual job using muscle power, the body locomotive organs, by sitting on the floor, with simple mat, and legs straight to the front. A work position by a long sitting position on the flour makes the weaver have low physical activity[2, 3]. Physical activity is related to body mass index. Low physical activity can increase body mass index $[4,5]$. Body mass index is one of the markers of nutritional status related to obesity. Prior epidemiologic studies have shown that increasing body mass index (BMI) is associated with higher total cholesterol, low-density lipoprotein cholesterol (LDL) and Triglyserides (6).

\section{METHOD}

This research is a correlation study with cross-sectional design. The study was done to 26 respondents that were chosen by the saturated sampling method. Physical activity is categorized according to the International Physical Activity Questionnaire (IPAQ) category. The IPAQ is an international questionnaire designed to measure adult physical activity in the previous seven days [7]. BMI is measured by anthropometry and triglyceride and cholesterol levels are measured by dialysis autolyzes. The correlation between physical activity with BMI, Triglycerides dan cholesterol levels are analyzed with Spearman Rho

\section{RESULTS AND DISCUSSION}

The subjects in this study were 26 weavers of Pegringsingan woven in Tenganan village, Karangasem, all of whom were women with active weaving criteria for at least the last two years. The measurement results of the weaver's physical activity were obtained by the majority of weavers, namely, 


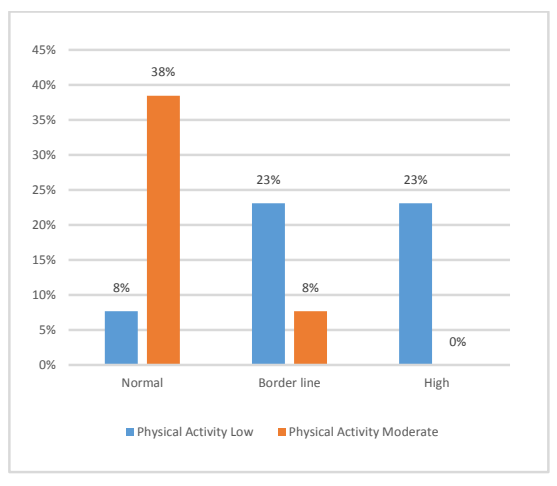

$54 \%$ had low physical activity and $46 \%$ had moderate physical activity. Most respondents did physical activity less than 600 METs-min / week.

Measurement of the respondent's Body Mass Index obtained results as much as $54 \%$ normal, $19 \%$ overweight and $27 \%$ obese. From the measurement of body mass index obtained the highest BMI is 40.5 and the lowest is 19.3 , with a mean value of 25 . Measurement of triglyceride levels found $46 \%$ had normal triglyceride levels, $31 \%$ triglyceride levels were at borderline and $23 \%$ had high triglyceride levels. the highest triglyceride level is $378 \mathrm{mg} / \mathrm{dl}$, while the lowest level is $68 \mathrm{mg} / \mathrm{dl}$, with a mean value of $153 \mathrm{mg} / \mathrm{dl}$. Measurement of cholesterol levels obtained $23 \%$ of cholesterol levels are good, $27 \%$ borderline and 50\% high cholesterol levels. The highest cholesterol level is 291 $\mathrm{mg} / \mathrm{dl}$ with the mean value $214 \mathrm{mg} / \mathrm{dl}$.

Most respondents with low physical activity have an over weight and obese Body Mass Index. 38\% of respondents who have a normal Body Mass Index are respondents with moderate physical activity.

Distribution of Body Mass Index based on Physical Activity can be seen in Figure 1.

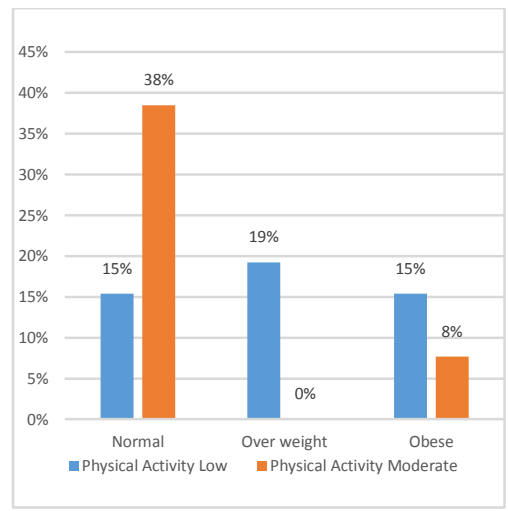

Figure 1. Distribution of Body Mass Index based on Physical Activity

The distribution of triglyceride levels, $38 \%$ of respondents with normal triglyceride levels were respondents with moderate physical activity, while respondents with high triglyceride levels all had low physical activity. The distribution of triglyceride levels, based on physical activity can be seen in Figure 2.
Figure 2. Distribution Of Triglyceride Levels Based On Physical Activity

Most respondents who have cholesterol levels at the threshold and high, have low physical activity. The distribution of cholesterol levels based on physical activity can be seen in Figure 3.

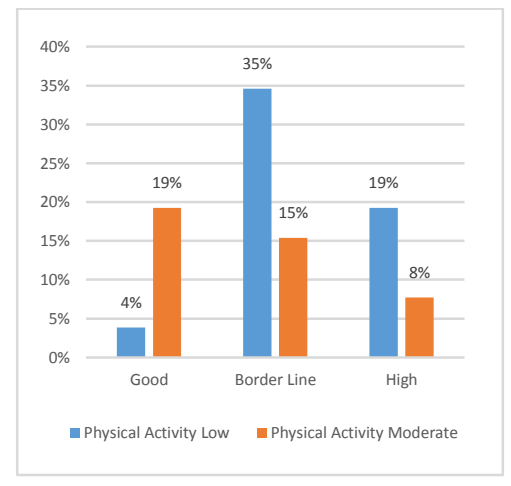

Figure 3. The Distribution of Cholesterol Levels Based On Physical Activity

The results of the Shapiro Wilk analysis data are not normally distributed. Correlation analysis was performed with the Spearman Rho analysis [8]. There is a significant correlation between physical activity with BMI $(p=0,021$; $r=-0,451)$, there is a significant correlation between physical activity with triglyceride levels $(\mathrm{p}=0,002 ; \mathrm{r}=$ 0,578 ), there is a significant correlation between physical activity with cholesterol levels $(\mathrm{p}=0,034 ; \mathrm{r}=-0,417)$.

The weaver's physical activity is a mostly low activity because weaving work requires sitting time of 6 to 8 hours per day so that the physical activity carried out by the weaver is less than 600 METs-min / week [9]. Physical activity associated with Body Mass Index, if physical activity is low then the Body Mass Index increases. As many as $46 \%$ of the body mass index of the weaver is more than $25 \mathrm{~kg} / \mathrm{m} 2$ or above normal. The excessive fat accumulation that occurs in obese people results in an increase in the amount of free fatty acids (Free Fatty Acid / FFA) that are hydrolyzed by endothelial lipoprotein lipase (LPL). This increase triggers the production of oxidants which have a negative effect on the endoplasmic and 
objectively measured physical activity and body mass index with low back pain: A large-scale cross-sectional study of Japanese men. BMC Public Health [Internet]. 2018;18(1):1-8. Available from: https://bmcpublichealth.biomedcentral.com/track/pdf/10.1 186/s12889-018-5253-8

[6] Lior ShamaiEinar LurixMichael ShenGian M. NovaroSamuel SzomsteinRaul Rosenthal. Association of Body Mass Index and Lipid Profiles: Evaluation of a Broad Spectrum of Body Mass Index Patients Including the Morbidly Obese. Obes Surg [Internet]. 2011;vol 21(1):42$7 . \quad$ Available from: https://link.springer.com/article/10.1007\%2Fs11695-010$0170-7$

[7] Hallal PC, Victora CG. Reliability and validity of the International Physical Activity Questionnaire (IPAQ) [2]. Med Sci Sports Exerc [Internet]. 2004;36(3):556. Available from: https://dev-journals2013.lww.com/acsmmsse/Fulltext/2004/03000/RELIABILITY AND VALIDI TY_OF_THE_INTERNATIONAL.00027.aspx

[8] McDonald JH. Handbook of Biological Statistics. 2014.

[9] Forde C. Scoring the International Physical Activity Questionnaire (IPAQ) Exercise Prescription for the Prevention and Treatment of Disease. 2005;(2005). Available from: https://ugc.futurelearn.com/uploads/files/bc/c5/bcc53b14ec1e-4d90-88e3-1568682f32ae/IPAQ_PDF.pdf

[10] Hong Hanh NT, Tuyet LT, Anh Dao DT, Tao Y, Chu DT. Childhood obesity is a High-risk factor for hypertriglyceridemia: A case-control study in Vietnam. Osong Public Heal Res Perspect [Internet]. 2017;8(2):13846. Available from: https://www.ncbi.nlm.nih.gov/pmc/articles/PMC5441441/ pdf/phrp-08-138.pdf

[11] Klop B, Elte JWF, Cabezas MC. Dyslipidemia in Obesity: Mechanisms and Potential Targets. Nutrients [Internet]. 2013;5(4):1218-40. Available from: https://www.ncbi.nlm.nih.gov/pmc/articles/PMC3705344/ pdf/nutrients-05-01218.pdf

[12] Hu G, Barengo NC, Tuomilehto J, Lakka TA, Nissinen A, Jousilahti P. Relationship of Physical Activity and Body Mass Index to the Risk of Hypertension: A Prospective Study in Finland. Hypertension [Internet]. 2004;43(1):25-30. Available from: https://www.ahajournals.org/doi/pdf/10.1161/01.HYP.000 0107400.72456 .19

[13] Hu SS, Kong LZ, Gao RL, Zhu ML, Wang W, Wang YJ, et al. Outline of the Report on Cardiovascular Disease in China, 2010. Biomed Environ Sci [Internet]. 2012;25(3):251-6. Available from: http://dx.doi.org/10.3967/0895-3988.2012.03.001
[5] Hashimoto Y, Matsudaira K, Sawada SS, Gando Y, Kawakami R, Sloan RA, et al. Association between 